ESRI

RESEARCH BULLETIN

NOVEMBER 2018

\section{HOW MANY BEDS?}

CAPACITY IMPLICATIONS OF HOSPITAL CARE DEMAND PROJECTIONS IN THE IRISH HOSPITAL SYSTEM, 2015-2030

CONOR KEEGAN, AOIFE BRICK, BRENDAN WALSH, ADELE BERGIN, JAMES EIGHAN, MAEV-ANN WREN

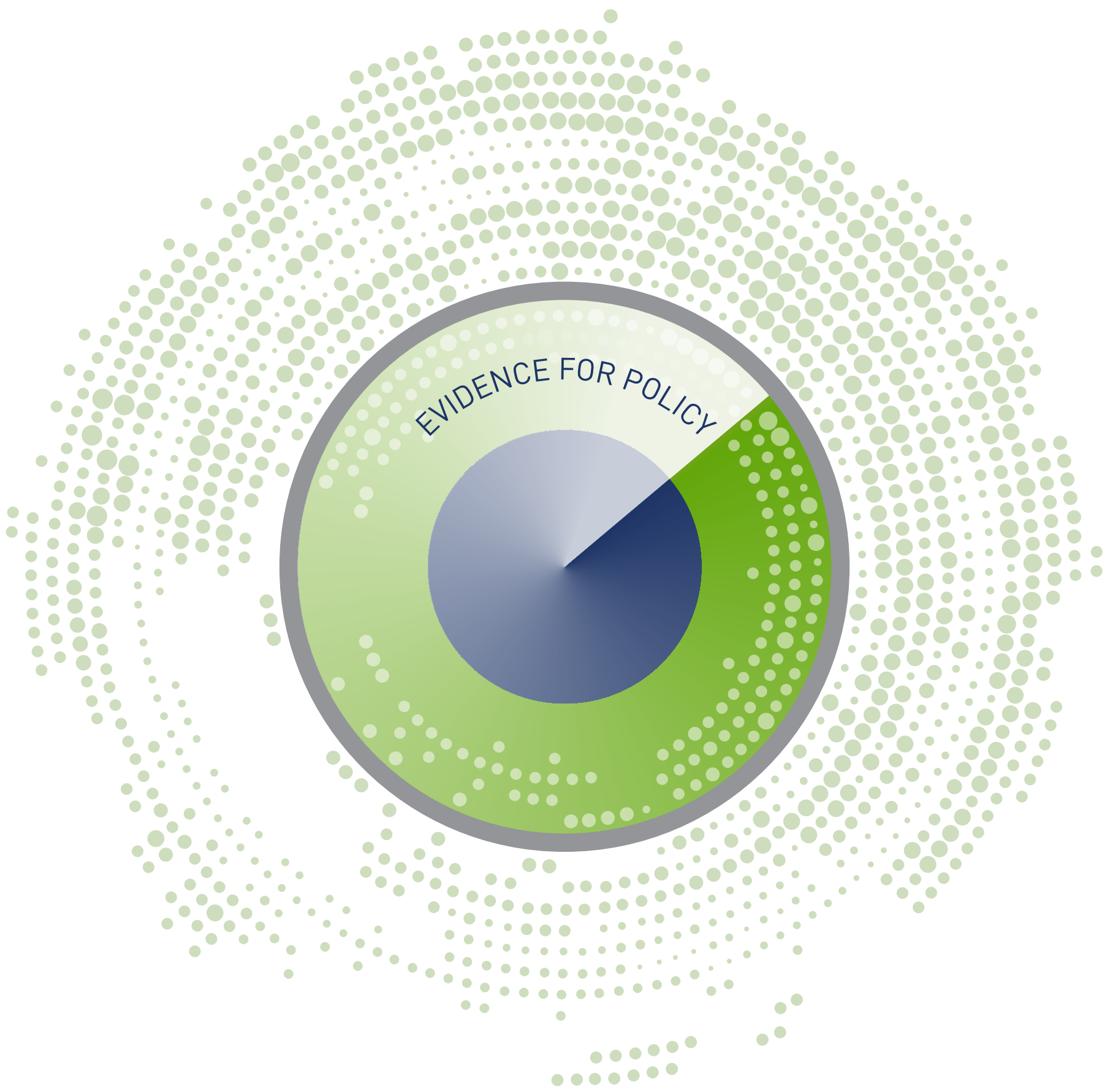




\title{
How many beds? Capacity implications of hospital care demand projections in the Irish hospital system, 2015-20301
}

*Conor Keegan (ESRI), Aoife Brick (ESRI), Brendan Walsh (ESRI), Adele Bergin (ESRI), James Eighan (Indecon), Maev-Ann Wren (ESRI)

\section{ESRI Research Bulletins provide short summaries of work published by ESRI researchers and overviews of thematic areas covered by ESRI programmes of research. Bulletins are designed to be easily accessible to a wide readership.}

\begin{abstract}
INTRODUCTION
The Irish hospital system at present does not have enough hospital beds to meet demand for care adequately. When measured against other OECD countries, Ireland has a low supply of hospital beds and records the highest rate of patient bed occupancy at 95 per cent. The expected rapid growth and ageing of the Irish population is projected to increase demand for hospital care further. This means that in the coming years there will be an even greater need to increase the number of available hospital beds. This paper employs the ESRI HIPPOCRATES healthcare projection model to project the number of public and private hospital beds that may be required between 2015 and 2030. Importantly, in developing these projections we take into account the ability to move care to non-hospital settings.
\end{abstract}

\section{DATA AND Methods}

Data for public hospital activity in 2015 are taken from the Hospital In-patient Enquiry (HIPE) Scheme which captures information on discharges from, and deaths in, acute public hospitals nationally. Activity in private hospitals is estimated by combining information on health insurer claims and privately-insured activity in public hospitals in 2015. Population projections are developed in-house in the ESRI and are based on 2016 Census data.

Demand for public and private hospital day patient and in-patient cases is projected and the number of hospital beds required to meet this demand is estimated. We provide a range of projections based on alternative assumptions on population growth and ageing; healthy ageing; unmet demand (the numbers

\footnotetext{
${ }^{1}$ This Bulletin summarises the findings from: Keegan, C., Brick, A., Walsh, B., Bergin, A., Eighan, J., and Wren, M-A., "How many beds? Capacity implications of hospital care demand projections in the Irish hospital system, 2015-2030", Int J Health Plann Mgmt, Available online: https://doi.org/10.1002/hpm.2673
} 
currently on waiting lists); hospital occupancy; hospital average length of stay; and avoidable hospitalisations.

\section{FINDINGS}

Between 2015 and 2030 we project a need for between an additional 4,000 and 6,300 beds in public and private hospitals combined. This represents an increase in bed numbers of between 26.1 and 41.1 per cent over this period. These large projected increases in demand for hospital beds are primarily driven by the effect of large projected growth and ageing of the Irish population in the coming years.

Between 3,200 and 5,600 of these additional beds are projected to be required in public hospitals. While evidence on the ability to substitute non-acute care for acute care is mixed, the projected demand for 3,200 additional beds at the lower end of this range is based on assumptions that investment in and improved access to primary and social care will help to reduce the level of need for additional public hospital beds.

The private hospital system plays an important and interconnected role in meeting demand for hospital care in the Irish system and projected demographic change will also have implications for future bed capacity requirements in private hospitals. We project that between 780 and 1,200 additional hospital beds will be required in the private hospital system by 2030 .

\section{POLICY IMPLICATIONS}

These findings suggest that the Irish Government's National Development Plan commitment to increase public acute bed capacity by 2,600 in the years to 2027 may not be sufficient to meet demand out to 2030. At the lower end of our range we project an extra 3,200 public hospital beds will be required by 2030 .

Increased investment in bed capacity will require related investment in the workforce. Current issues in terms of recruitment and retention of medical staff in the public health system particularly need to be addressed as a part of the wider need to increase bed supply. 
Whitaker Square,

Sir John Rogerson's Quay,

Dublin 2

Telephone +353 18632000

Email admin@esri.ie

Web www.esri.ie

Twitter @ESRIDublin 